\title{
Field-Induced Single-Molecule Magnets of Dysprosium Involving Quinone Derivatives
}

\author{
Konstantin Martyanov ${ }^{1}{ }^{\circledR}$, Jessica Flores Gonzalez ${ }^{2}{ }^{\circledR}$, Sergey Norkov ${ }^{1}{ }^{(}$, Bertrand Lefeuvre $^{2}$, Vincent Dorcet $^{2}$, \\ Vladimir Cherkasov ${ }^{1}\left(\mathbb{D}\right.$, Olivier Cador ${ }^{2}$, Viacheslav Kuropatov ${ }^{1, * \mathbb{D}}$ and Fabrice Pointillart $2, * \mathbb{D}$ \\ 1 G. A. Razuvaev Institute of Organometallic Chemistry of Russian Academy of Sciences, box 445, \\ Tropinina str., 49, Nizhny Novgorod 603950, Russia; konmart@iomc.ras.ru (K.M.); norkov@iomc.ras.ru (S.N.); \\ cherkasov@iomc.ras.ru (V.C.) \\ 2 ISCR (Institut des Sciences Chimiques de Rennes)-UMR 6226, CNRS, Université Rennes, \\ F-35000 Rennes, France; jessica.flores-gonzales@univ-rennes1.fr (J.F.G.); \\ bertrand.lefeuvre@univ-rennes1.fr (B.L.); vincent.dorcet@univ-rennes1.fr (V.D.); \\ olivier.cador@univ-rennes1.fr (O.C.) \\ * Correspondence: viach@iomc.ras.ru (V.K.); fabrice.pointillart@univ-rennes1.fr (F.P.)
}

\section{check for} updates

Citation: Martyanov, K.; Flores Gonzalez, J.; Norkov, S.; Lefeuvre, B.; Dorcet, V.; Cherkasov, V.; Cador, O.; Kuropatov, V.; Pointillart, F.

Field-Induced Single-Molecule Magnets of Dysprosium Involving Quinone Derivatives.

Magnetochemistry 2021, 7, 24.

https://doi.org/10.3390/

magnetochemistry7020024

Academic Editors: Floriana Tuna and Lorenzo Sorace

Received: 16 December 2020

Accepted: 4 February 2021

Published: 6 February 2021

Publisher's Note: MDPI stays neutral with regard to jurisdictional claims in published maps and institutional affiliations.

Copyright: (c) 2021 by the authors. Licensee MDPI, Basel, Switzerland. This article is an open access article distributed under the terms and conditions of the Creative Commons Attribution (CC BY) license (https:/ / creativecommons.org/licenses/by/ $4.0 /)$.

\begin{abstract}
The coordination reaction of the [Dy(hfac) ${ }_{3}\left(\mathrm{H}_{2} \mathrm{O}\right)_{2}$ ] units (hfac ${ }^{-}=1,1,1,5,5,5-$ hexafluoroacetylacetonate) with the two quinone-based derivatives 4,7-di-tert-butyl-2-(3,5-di-tert-butyl-4oxocyclohexa-2,5-dien-1-ylidene)benzo[d][1,3]dithiole-5,6-dione $\left(\mathbf{L}^{\mathbf{1}}\right)$ and 7,8-dithiabicyclo[4.2.0]octa-1,5diene-3,4-dione,2,5bis(1,1-dimethylethyl) $\left(\mathbf{L}^{\mathbf{2}}\right)$ led respectively to the complexes [Dy(hfac) $\left.{ }_{3}\left(\mathrm{H}_{2} \mathrm{O}\right)\left(\mathbf{L}^{\mathbf{1}}\right)\right](\mathbf{1})$ and $\left[\mathrm{Dy}(\mathrm{hfac})_{3}\left(\mathrm{H}_{2} \mathrm{O}\right)\left(\mathbf{L}^{2}\right)\right] \cdot\left(\mathrm{C}_{6} \mathrm{H}_{14}\right)\left(\mathrm{CH}_{2} \mathrm{Cl}_{2}\right)(2) \cdot\left(\mathrm{C}_{6} \mathrm{H}_{14}\right)\left(\mathrm{CH}_{2} \mathrm{Cl}_{2}\right)$. X-ray structures on single crystal of 1 and 2. $\left(\mathrm{C}_{6} \mathrm{H}_{14}\right)\left(\mathrm{CH}_{2} \mathrm{Cl}_{2}\right)$ revealed the coordination of the $\mathrm{Dy}^{\mathrm{III}}$ on the bischelating oxygenated quinone site and the formation of dimeric species through hydrogen bonds. Ac magnetic measurements highlighted field-induced single-molecule magnet behavior with magnetic relaxation through a Raman process.
\end{abstract}

Keywords: dysprosium; $\beta$-diketonate; o-quinone; dithiolene; regioselectivity; single molecule magnets

\section{Introduction}

The design of the coordination surrounding of magneto-active ions is a challenging task; a choice of o-quinone-like dioxolenes for this purpose seems to be promising for several reasons: (i) o-dioxolenes possess a redox activity, their oxidation state may be changed directly in the coordination sphere of the metal ion [1-3]. Organic radical semiquinone form is often associated to transition metal to design complexes displaying chemical and physical properties, such as valence tautomerism [4], photo-and thermo-mechanical effects [5]. o-Quinone-like dioxolenes in quinone, semiquinone [6-9] or catecholate [10-12] oxidation states have been associated with lanthanide ions to generate luminescence [13] and single-molecule magnet (SMM) behavior [14-16], as well as magnetic or optical switching [17-20]. It is worth mentioning that SMM behavior is associated to the observation of slow magnetic relaxation at the molecular scale, leading to the opening of a hysteresis loop at low temperature. The recent discovery of organometallic complexes of dysprosium with high blocking temperature [21-24] make them potential candidates for high density data storage; (ii) due to chelating ability, o-dioxolenes form stable complexes with almost all metals; (iii) o-quinone may be modified with various additional redox-active, free radical bearing or coordination-capable functional fragments to provide possibilities for the switching of the redox and/or magnetic state of the molecule [25].

The interest for metal dithiolenes emerged due to their potential applications in molecular conductors and superconductors [26]. Moreover, they have been recently employed to study electronic spin decoherence for quantum computation [27-29].

The two following o-quinone derivatives, 4,7-di-tert-butyl-2-(3,5-di-tert-butyl-4oxocyclohexa-2,5-dien-1-ylidene)benzo[d][1,3]dithiole-5,6-dione $\left(\mathbf{L}^{\mathbf{1}}\right)$ [30] and 7,8-dithiabicyclo 
octa-1,5-diene-3,4-dione,2,5bis(1,1-dimethylethyl) $\left(\mathbf{L}^{2}\right)$ [31] (Chart 1), have been selected to be involved in coordination reaction with the $\left[\mathrm{Dy}(\mathrm{hfac})_{3}\left(\mathrm{H}_{2} \mathrm{O}\right)_{2}\right]$ precursor $(\mathrm{hfac}=1,1,1,5,5,5$ hexafluoroacetylacetone) (Scheme $\mathbf{S 1}$ ). $\mathbf{L}^{2}$ is a multi-chelating ligand which presents both 1,2-dithiolene and 1,2-dioxolene coordination sites. Some of us previously demonstrated that single- and two-electrons reduction led to the respective formation of semiquinonate species and catecholate or dithiolate species depending on the nature of the metallofragments. Moreover, a regioselectivity of the coordination reaction was observed depending on the hard or soft acidity of the metal ion [31-34].<smiles>CC(C)(C)C1=CC(=C2SC3=C(C(C)(C)C)C(=O)C(=O)C(C(C)(C)C)=C3S2)C=C(C(C)(C)C)C1=O</smiles>

$L^{1}$<smiles></smiles>

$\mathrm{L}^{2}$

Chart 1. Molecular structure of $\mathbf{L}^{1}$ and $\mathbf{L}^{2}$ ligands.

In the present paper, the reaction between $\mathbf{L}^{\mathbf{1}}$ or $\mathbf{L}^{2}$ in presence of $\left[\mathrm{Dy}(\mathrm{hfac})_{3}\left(\mathrm{H}_{2} \mathrm{O}\right)_{2}\right]$ led to the coordination on the 1,2-quinone site (regioselectively in case of $\mathbf{L}^{2}$ ) without reduction of it. Magnetic properties of the resulting [Dy $\left.(\mathrm{hfac})_{3}\left(\mathrm{H}_{2} \mathrm{O}\right)\left(\mathbf{L}^{\mathbf{1}}\right)\right](\mathbf{1})$ and $\left[\mathrm{Dy}(\mathrm{hfac})_{3}\left(\mathrm{H}_{2} \mathrm{O}\right)\left(\mathbf{L}^{2}\right)\right]$ $\cdot\left(\mathrm{C}_{6} \mathrm{H}_{14}\right)\left(\mathrm{CH}_{2} \mathrm{Cl}_{2}\right)(2) \cdot\left(\mathrm{C}_{6} \mathrm{H}_{14}\right)\left(\mathrm{CH}_{2} \mathrm{Cl}_{2}\right)$ complexes are investigated.

\section{Results and Discussion}

\subsection{X-ray Structures}

4,7-di-tert-butyl-2-(3,5-di-tert-butyl-4-oxocyclohexa-2,5-dien-1-ylidene)benzo[d][1,3]dithiole5,6-dione $\left(\boldsymbol{L}^{1}\right)$. This ligand was recently reported by some of us [30]. The IR and NMR data are given in SI. In order to have an optimal structural comparison between the free $\mathbf{L}^{\mathbf{1}}$ quinone and the corresponding coordination complex (1), its X-ray structure was determined at $150 \mathrm{~K}$ on dark purple single crystals obtained from $n$-hexane-ether solution on cooling. A quick description is given in the following lines. $\mathbf{L}^{\mathbf{1}}$ crystallized in the tetragonal space group P-4 ( $\left.{ }^{\circ} 81\right)$ (Figure S1 and Table S1). The asymmetric unit is composed of one almost planar organic molecule of $\mathbf{L}^{1}$. The three $\mathrm{C}=\mathrm{O}$ distances range from 1.197(3) to 1.233(4) $\AA$, which is consistent with a double bond character. Alternated bond lengths distribution in the dioxolene ring of $\mathbf{L}^{\mathbf{1}}$ is also typical of sterically hindered o-quinones. Thus, the single crystal X-ray structure confirmed the quinone form of $\mathbf{L}^{1}$ at $150 \mathrm{~K}$. The crystal packing of $\mathbf{L}^{1}$ revealed a stacking of the molecules along the c axis; nevertheless, the bulky tert-butyl groups prevented any strong $\pi-\pi$ interaction. Thus, the cohesion of the

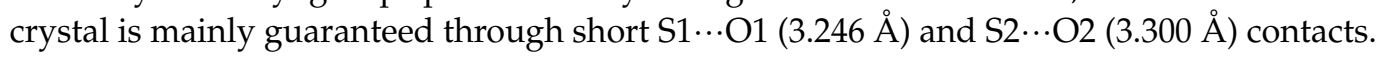
One could remark that to optimize the overlap between the $\pi$ orbitals of the oxygen and sulfur atoms, the quinone fragment is not planar (Figure 1).

$\left[D y(h f a c)_{3}\left(H_{2} O\right)\left(L^{1}\right)\right](\mathbf{1})$. The coordination reaction of the tris $(1,1,1,5,5,5$-hexafluoroacetylacetonate)bis(aqueous)Dy ${ }^{\mathrm{III}}\left(\left[\mathrm{Dy}(\mathrm{hfac})_{3}\left(\mathrm{H}_{2} \mathrm{O}\right)_{2}\right]\right)$ with 4,7-di-tert-butyl-2-(3,5-di-tertbutyl-4-oxocyclohexa-2,5-dien-1-ylidene)benzo[d][1,3] dithiole-5,6-dione ( $\left.\mathbf{L}^{\mathbf{1}}\right)$ [30] (Chart 1) in $\mathrm{CH}_{2} \mathrm{Cl}_{2}$ led to the formation of the complexes [Dy $\left.(\mathrm{hfac})_{3}\left(\mathrm{H}_{2} \mathrm{O}\right)\left(\mathbf{L}^{\mathbf{1}}\right)\right](\mathbf{1})$. Moreover, $\mathbf{1}$ crystallized in the monoclinic space group C2/c (Table S1) and an ORTEP view of the asymmetric unit is depicted in Figure S1. The latter is composed of one complex of formula [Dy $\left.(\mathrm{hfac})_{3}\left(\mathrm{H}_{2} \mathrm{O}\right)\left(\mathbf{L}^{\mathbf{1}}\right)\right]$ (Figure 1a). The mononuclear species is formed by coordination of the bischelating quinone fragment to the $\mathrm{Dy}{ }^{\mathrm{III}}$ metal center. The quinone character is confirmed by the two C16 = O7 (1.240(5) $\AA$ ) and C21 = O8 (1.236(5) $\AA$ ) bond lengths. The dioxolene ring of the ligand in $\mathbf{1}$ also retains an alternated (non-aromatic) distribution of 
bond lengths. The coordination sphere of the Dy ${ }^{\mathrm{III}}$ is filled by three bischelating hfac ${ }^{-}$ anions and one water molecule. The arrangement of the $\mathbf{L}^{\mathbf{1}}$, the three $\mathrm{hfac}^{-}$anions and the coordinated water molecule formed a polyhedron, having a $C_{4 v}$ spherical capped square antiprism as the closest ideal symmetry (Table S2). The deviations from the ideal symmetries are calculated using the SHAPE software [35].

(a)

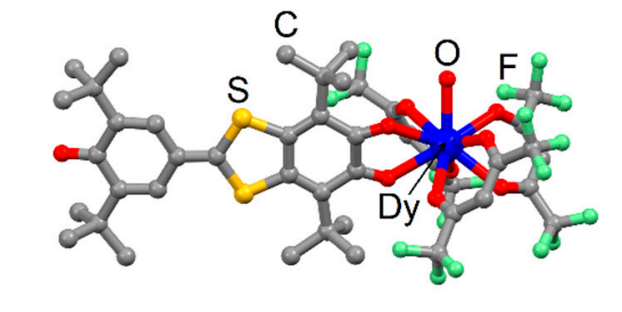

(c)

(a)
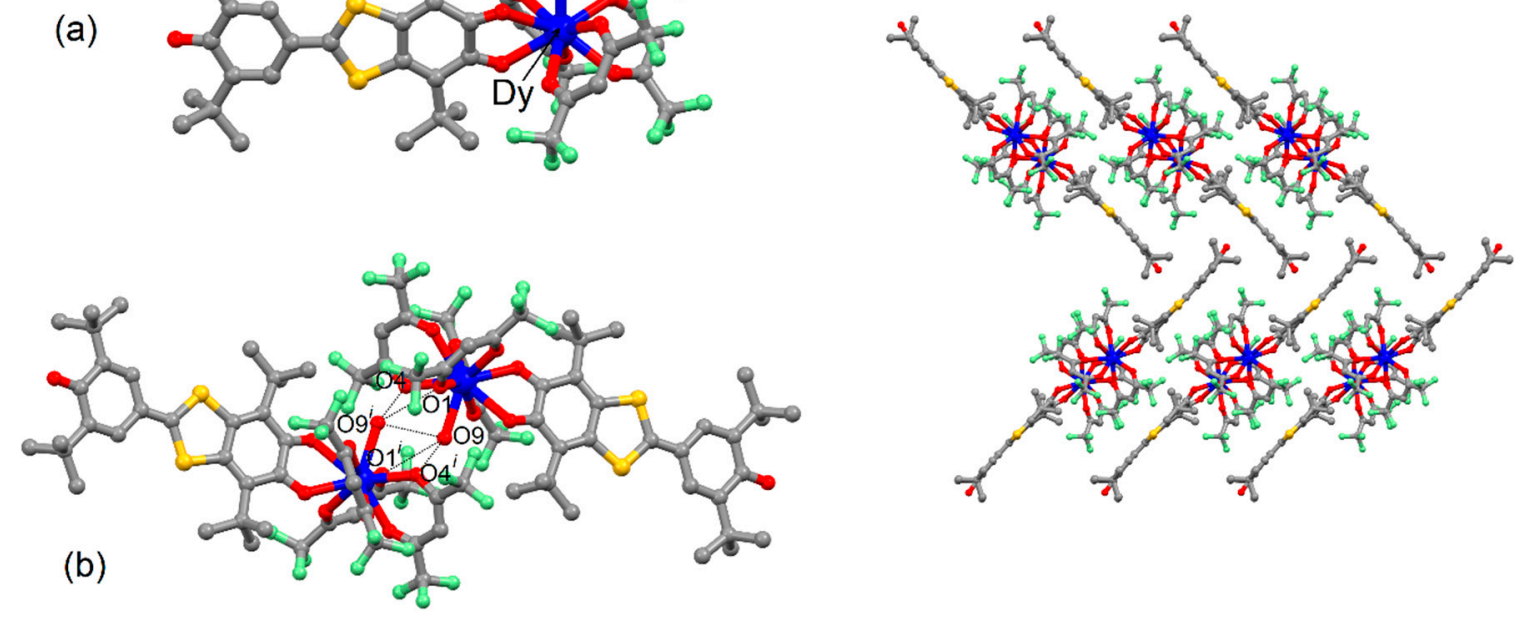

Figure 1. (a) Molecular structure, (b) formation of the dimer through multiple hydrogen bonds highlighting in dashed lines and (c) the crystal packing along the $b$ axis for 1 . Color code: gray: carbon, blue: dysprosium, red: oxygen, green: fluorine and yellow: sulfur.

The coordination to the $\left[\mathrm{Dy}(\mathrm{hfac})_{3}\left(\mathrm{H}_{2} \mathrm{O}\right)\right]$ unit makes similar short $\mathrm{S}$.. O contacts like those observed for the $\mathrm{X}$-ray structure of the free $\mathbf{L}^{\mathbf{1}}$ ligand impossible. Consequently, the arrangement of the quinone changed with carbonyl groups on either side of the plane formed by the six-membered ring of the quinone. The crystal packing revealed the formation of a dimeric structure through hydrogen bonds thanks to the coordinated water molecule. Five short $\mathrm{O} \cdots \mathrm{O}$ contacts ranging from $2.873 \AA$ to $2.965 \AA$ have been identified, leading to a Dy ‥Dy intermolecular distance of $5.981 \AA$ (Figure 1b). The shortest intermolecular Dy …Dy distance not involved in a dimer was measured at $10.579 \AA$.

Finally, the dimers of $\mathbf{1}$ were organized in a parallel way along the $b$ axis, while the quinone derivatives $\mathbf{L}^{\mathbf{1}}$ were organized in an orthogonal way with the neighboring $\mathbf{L}^{\mathbf{1}}$ (Figure 1c). Such arrangement allowed the carbonyl group involving the $\mathrm{O} 10$ atom to point towards the two sulfur atoms of the neighboring molecule leading to $\mathrm{O} 10 \cdots \mathrm{S} 1$ and $\mathrm{O} 10 \cdots \mathrm{S} 2$ distances of $3.934 \AA$ and $3.536 \AA$ (Figure S2).

$\left[D y(h f a c)_{3}\left(\mathrm{H}_{2} \mathrm{O}\right)\left(\mathbf{L}^{2}\right)\right] \cdot\left(\mathrm{C}_{6} \mathrm{H}_{14}\right)\left(\mathrm{CH}_{2} \mathrm{Cl}_{2}\right)(2) \cdot\left(\mathrm{C}_{6} \mathrm{H}_{14}\right)\left(\mathrm{CH}_{2} \mathrm{Cl}_{2}\right)$. The coordination reaction of the tris $\left(1,1,1,5,5,5\right.$-hexafluoroacetylacetonate)bis(aqueous)Dy ${ }^{\mathrm{III}}\left(\left[\mathrm{Dy}(\mathrm{hfac})_{3}\left(\mathrm{H}_{2} \mathrm{O}\right)_{2}\right]\right)$ with 7,8-dithiabicyclo[4.2.0]octa-1,5-diene-3,4-dione,2,5bis(1,1-dimethylethyl) $\left(\mathbf{L}^{2}\right)$ [26] (Chart 1) in $\mathrm{CH}_{2} \mathrm{Cl}_{2}$ led to the formation of the complexes [Dy $\left.(\mathrm{hfac})_{3}\left(\mathrm{H}_{2} \mathrm{O}\right)\left(\mathrm{L}^{2}\right)\right] \cdot\left(\mathrm{C}_{6} \mathrm{H}_{14}\right)\left(\mathrm{CH}_{2} \mathrm{Cl}_{2}\right)$ ((2). $\left.\left(\mathrm{C}_{6} \mathrm{H}_{14}\right)\left(\mathrm{CH}_{2} \mathrm{Cl}_{2}\right)\right) \cdot 2 \cdot\left(\mathrm{C}_{6} \mathrm{H}_{14}\right)\left(\mathrm{CH}_{2} \mathrm{Cl}_{2}\right)$ crystallized in the monoclinic space group $\mathrm{P} 21$ (Table S1). The asymmetric unit is composed of eight molecules [Dy $\left.(\mathrm{hfac})_{3}\left(\mathrm{H}_{2} \mathrm{O}\right)\left(\mathbf{L}^{2}\right)\right]$ (Figure 2a) and its ORTEP view is shown in Figures S3 and S4. The bischelating dioxolene site in a quinone form is coordinated to the $\left[\mathrm{Dy}(\mathrm{hfac})_{3}\left(\mathrm{H}_{2} \mathrm{O}\right)\right]$ unit, in agreement with the oxophilic character of the lanthanide ion, in contrast with what was observed for the bischelating dithiolene coordination site, which is coordinated to the soft $\mathrm{Pd}^{\mathrm{II}}$ [34]. The quinone form of $\mathbf{L}^{2}$ was confirmed by the $\mathrm{C}=\mathrm{O}$ bond lengths, ranging from $1.064 \AA$ to $1.417 \AA$ (average distance of $1.230 \AA$ ). The coordination sphere of the Dy ${ }^{I I I}$ is filled with three bischelating $\mathrm{hfac}^{-}$anions and one water molecule. The deviations from the ideal symmetries for each Dy ${ }^{\mathrm{III}}$ surrounding are calculated using the SHAPE software 
(Table S3) [35]. The eight coordination polyhedron symmetries corresponding to the eight crystallographically independent dysprosium can be classified into two groups, with Dy1, Dy2 and Dy5 adopting a $\mathrm{D}_{3 \mathrm{~h}}$ spherical tricapped trigonal prism, while the five others adopted a $\mathrm{C}_{4 \mathrm{v}}$ spherical capped square antiprism. Since one water molecule coordinated to the $\mathrm{Dy}^{\mathrm{III}}$ is present, the formation of dimers through hydrogen bonds is observed (Figure $2 \mathrm{~b}$ ). For each dimer, three short $\mathrm{O} \cdots \mathrm{O}$ contacts ranging from $2.653 \AA$ to $3.039 \AA$ have been identified, leading to an average Dy $\cdots$ Dy intermolecular distance of $5.868 \AA$. The shortest intermolecular Dy...Dy distance not involved in a dimer was measured at $9.657 \AA$. $\mathrm{H} \cdots \mathrm{F}$ and $\mathrm{F} \cdots \mathrm{F}$ contacts ensured the cohesion between the different dimers (Figure S5).
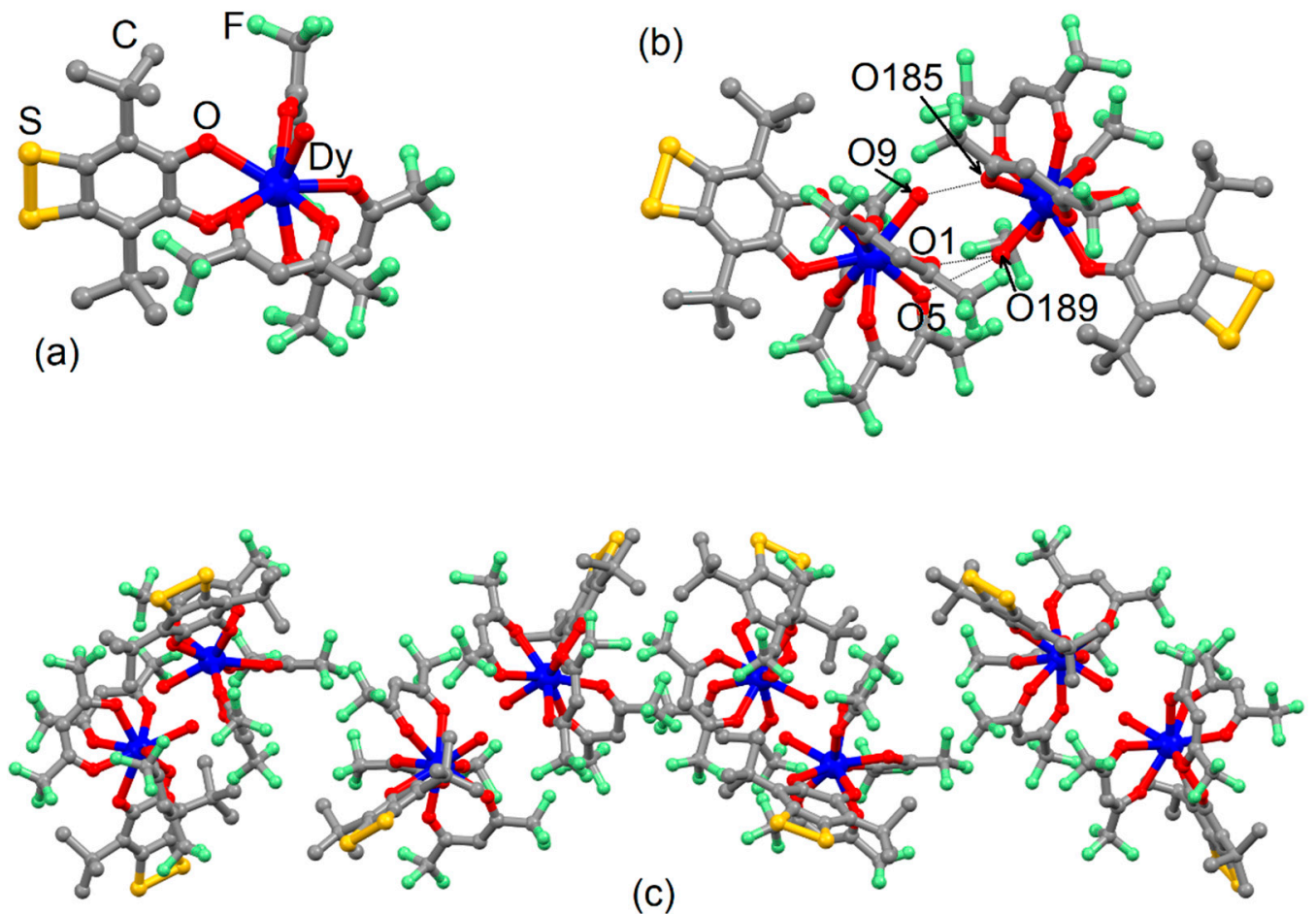

Figure 2. (a) Molecular structure, (b) formation of the dimer through multiple hydrogen bonds highlighting in dashed lines and (c) the crystal packing in the plan (101) for 2. Color code: gray: carbon, blue: dysprosium, red: oxygen, green: fluorine and yellow: sulfur.

One could remark that even if both X-ray structures of $\mathbf{1}$ and $\mathbf{2} \cdot\left(\mathrm{C}_{6} \mathrm{H}_{14}\right)\left(\mathrm{CH}_{2} \mathrm{Cl}_{2}\right)$ involved similar dimerization of the complexes through hydrogen bond due to the remaining coordinated water molecules, a slight structural difference could be noticed. Indeed, the dimer of 1 involved both $\mathrm{O}_{\mathrm{w}} \cdots \mathrm{O}_{\mathrm{w}}\left(2.954 \AA\right.$ ) and $\mathrm{O}_{\mathrm{w}} \cdots \mathrm{O}_{\mathrm{hfac}}$ (average distance of $2.919 \AA$ ) short contacts, while in $2 \cdot\left(\mathrm{C}_{6} \mathrm{H}_{14}\right)\left(\mathrm{CH}_{2} \mathrm{Cl}_{2}\right)$, only $\mathrm{O}_{\mathrm{w}} \cdots \mathrm{O}_{\text {hfac }}$ (average distance of $2.835 \AA$ ) are involved. Previous systems, published by some of us, already showed that the coordination of the quinone-tetrathiafulvalene-quinone triad [14] or quinone-(extended-TTF)quinone triad [17] to the [Dy(hfac $)_{3}$ ] unit led to the observation of a remaining coordinated water molecule and such dimerization through $\mathrm{O}_{\mathrm{w}} \cdots \mathrm{O}_{\mathrm{hfac}}$ short contacts only. In others words, $\mathbf{1}$ is the only system showing $\mathrm{O}_{\mathrm{w}} \cdots \mathrm{O}_{\mathrm{w}}$ short contact susceptible to induce difference in the magnetic behavior.

\subsection{Magnetic Properties}

\subsubsection{Static Magnetic Measurements}

The magnetic susceptibility $\left(\chi_{M}\right)$ was measured for both $\mathbf{1}$ and $\mathbf{2}$ compounds in the temperature range of $2-300 \mathrm{~K}$ and their thermal dependence of the $\chi_{M} T$ products is depicted in Figure 3. The experimental room temperature values for $\mathbf{1}$ and $\mathbf{2}$ are respectively $13.62 \mathrm{~cm}^{3} \cdot \mathrm{K} \cdot \mathrm{mol}^{-1}$ and $13.77 \mathrm{~cm}^{3} \cdot \mathrm{K} \cdot \mathrm{mol}^{-1}$, in agreement with the expected value consider- 
ing one isolated Dy ${ }^{\text {III }}$ ion $\left({ }^{6} \mathrm{H}_{15 / 2}\right.$ ground state multiplet) $\left(14.17 \mathrm{~cm}^{3} \cdot \mathrm{K} \cdot \mathrm{mol}^{-1}\right)$ [32]. When decreasing the temperature, $\chi_{M} T$ products decrease monotonically down to $8.61 \mathrm{~cm}^{3} \cdot \mathrm{K} \cdot \mathrm{mol}^{-1}$ for $\mathbf{1}$ and $10.28 \mathrm{~cm}^{3} \cdot \mathrm{K} \cdot \mathrm{mol}^{-1}$ for 2 . Such magnetic behavior is attributed to the thermal depopulation of the $\mathrm{M}_{\mathrm{J}}$ states and antiferromagnetic dipolar interactions. Indeed, some of us demonstrated that the formation of dimer through hydrogen bonds led to antiferromagnetic interactions up to $-0.65 \mathrm{~cm}^{-1}$ between the two Dy III ions [17]. In such a situation, the observed $\chi_{M} T$ value at $2 \mathrm{~K}$ is close to $10 \mathrm{~cm}^{3} \cdot \mathrm{K} \cdot \mathrm{mol}^{-1}$, which is in agreement with the observed value for $\mathbf{2}$, while a lower value is observed for $\mathbf{1}$. Such a low value might be attributed to stronger antiferromagnetic interaction in $\mathbf{1}$ than in $\mathbf{2}$ and previously reported examples [14,17], because the $\mathrm{O}_{\mathrm{w}} \cdots \mathrm{O}_{\mathrm{w}}$ contact is the shortest one. Considering that the dipolar interaction is proportional to $1 / \mathrm{r}^{3}$ (where $\mathrm{r}^{3}$ is the distance between the two spin carriers), it is reasonable to consider that the inter-dimer dipolar interaction would be negligible compared to the intra-dimer dipolar interaction.

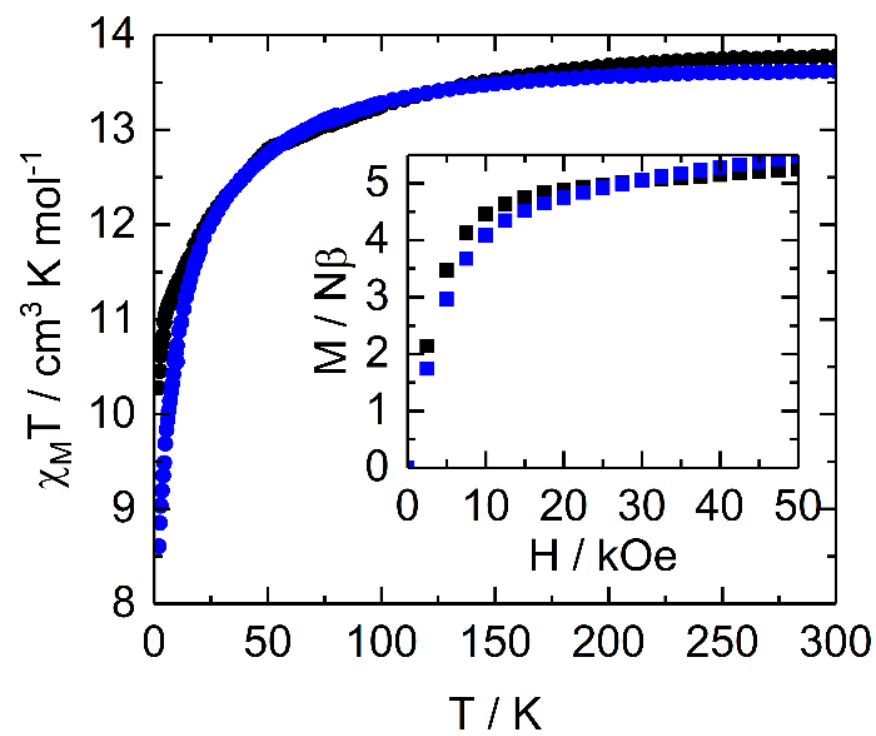

Figure 3. Temperature dependence of $\chi_{\mathrm{M}} \mathrm{T}$ for $\mathbf{1}$ (blue) and $\mathbf{2}$ (black) between 2 and $300 \mathrm{~K}$. In inset, the field variations of the magnetization at $2 \mathrm{~K}$ for $\mathbf{1}$ (blue) and $\mathbf{2}$ (black) between 0 and $50 \mathrm{kOe}$.

The measured magnetizations at $50 \mathrm{kOe}$ are $5.46 \mu_{\mathrm{B}}$ for $\mathbf{1}$ and $5.24 \mu_{\mathrm{B}}$ for $\mathbf{2}$ far from the expected saturated value of $10 \mu_{\mathrm{B}}$, due to the magnetic anisotropy of the systems (inset of Figure 3) [36]. The two magnetizations at $2 \mathrm{~K}$ showed significant differences, i.e., slower increase at low field for $\mathbf{1}$ than for $\mathbf{2}$, in agreement with possible stronger antiferromagnetic interaction in $\mathbf{1}$ than in $\mathbf{2}$. Moreover, the slope of the magnetization at higher fields might also suggest a different composition of the ground state. Thus, the nature of the $\mathrm{M}_{\mathrm{J}}$ ground doublet state could also play a role in the $\chi_{M} \mathrm{~T}$ low value for $\mathbf{1}$.

\subsubsection{Dynamic Magnetic Measurements}

The high magnetic moment and the strong magnetic anisotropy of the DyIII ion in an O9 surrounding could be suitable parameters to observe a slow relaxation of its magnetization $[14,17]$. The molar ac magnetic susceptibility $\left(\chi_{M}\right)$ was measured for both compounds $\mathbf{1}$ and $\mathbf{2}$ in order to study the dynamic magnetic properties. No out-of-phase signal $\left(\chi_{M}{ }^{\prime \prime}\right)$ was detected in zero magnetic field in the frequency range 1-1000 Hz for 1 (Figure S6) and the reason is usually imputed to a fast magnetic relaxation through a quantum tunneling of the magnetization (QTM). The latter can be cancelled, applying a dc magnetic field, as shown in Figure S6. The field dependence of the magnetic susceptibility revealed that a good compromise for the applied magnetic field value is 1600 Oe. Under such an applied field, 1 highlighted a frequency dependence of the magnetic susceptibility (Figure S7). An extended Debye model $[37,38]$ was used to extract the temperature dependence of the 
relaxation time, fitting simultaneously both $\chi_{M}{ }^{\prime}$ and $\chi_{M}{ }^{\prime \prime}$ (Figure S8 and Table S4), which are depicted in Figure 4.

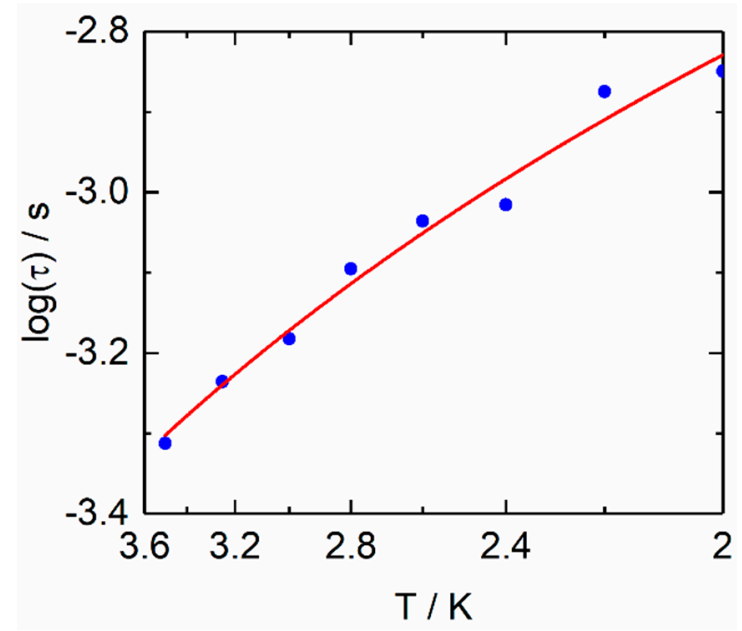

Figure 4. Temperature variation of the relaxation time for $\mathbf{1}$ in the temperature range of $2-3.5 \mathrm{~K}$ (blue spots) with the best fitted curve with a Raman process with $\mathrm{C}=175(19) \mathrm{s}^{-1} \mathrm{~K}^{-\mathrm{n}}$ and $n=1.95(11)$ (red line).

The full formula for the relaxation rate of the magnetization as a sum of the different possible contributing processes is given in the following Equation (1):

$$
\tau^{-1}=\tau_{0}^{-1} \exp \left(\frac{\Delta}{T}\right)+\underbrace{C T_{\text {Raman }}^{n}}_{\text {Orbach }}+\frac{\underbrace{\boldsymbol{B}_{1}}_{\tau_{T I}^{-1}, \mathrm{QTM}}}{1+\boldsymbol{B}_{2} H^{2}}+\underbrace{A T H^{m}}_{\text {Direct }}
$$

with the different relaxation rates standing for the Orbach, the Raman, the QTM (quantum tunneling of the magnetization), and the direct processes, respectively; and the different parameters $\left(\tau_{0}, \Delta, \tau_{T I}, n, C\right.$ and $A$ ) are found by fitting the experimental data, whereas $\mathrm{m}$ exponent is supposed to be tabulated and known values.

Since no high-frequency shift for the maxima of the out-of phase contribution was observed under an applied magnetic field, direct spin-phonon relaxation process was discarded. The relaxation time of the magnetization $(\tau)$ can be fitted using the thermally dependent Raman process only $\left(\tau^{-1}=\mathrm{CT}^{\mathrm{n}}\right)$. The best fit was obtained with the following parameters: $\mathrm{C}=175(19) \mathrm{s}^{-1} \mathrm{~K}^{-\mathrm{n}}$ and $n=1.95$ (11) (Figure 4 and Figure S9). The presence of both acoustic and optical phonons could induce the observation of $n$ values between 2 and 7 [39-41], instead of the expected $n$ value of 9 for Kramers ions [42]. It is worth noticing that the slow relaxation fraction is low (about $25 \%$ of the sample susceptibility) at $2 \mathrm{~K}$. The non-relaxing fraction was extracted from the extrapolation of the normalized Argand plot to the $x$-axis at a given temperature (Figure S10). Thus, the field dependence of the magnetic susceptibility was checked at higher frequency (Figure S6), showing that a non-zero contribution is present at a higher frequency than $10,000 \mathrm{~Hz}$.

In case of 2, an out-of phase component of the magnetic susceptibility was observed without applied magnetic field (Figure 5 and Figure S11) at $2 \mathrm{~K}$. Two contributions can be observed at $100 \mathrm{~Hz}$ and higher than 10,000 Hz. Application of a dc field induced a shift of the two $\chi_{M}$ " contributions at lower frequency. The value of 1200 Oe was selected as the optimal field. Under the 1200 Oe applied field, a frequency dependence of the magnetic susceptibility was observed (Figure 5 and Figure S12). 


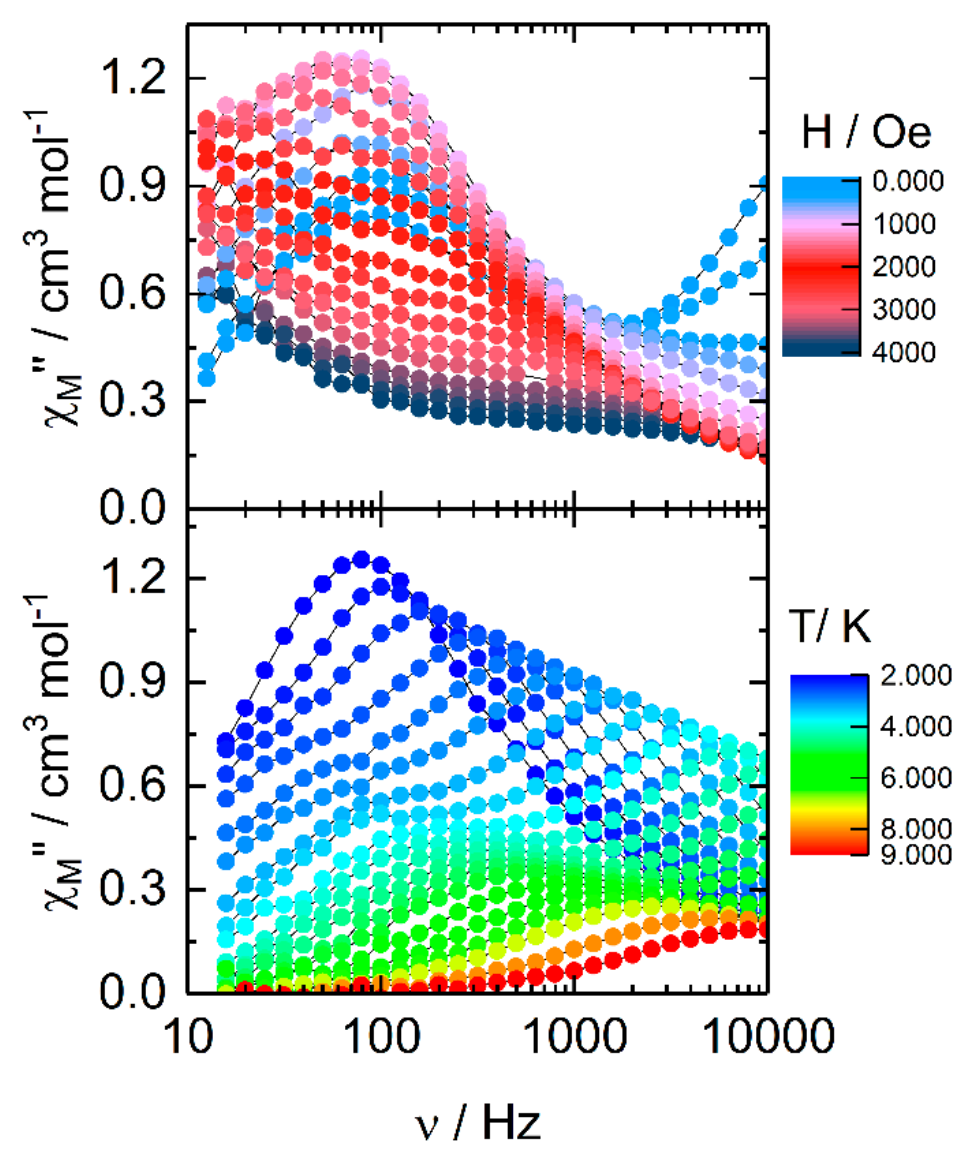

Figure 5. (Above) field dependence of the out-of-phase contribution of the magnetic susceptibility between 0 and 4000 Oe at $2 \mathrm{~K}$ for 2. (Below) Frequency dependence of the out-of-phase contribution of the magnetic susceptibility between 2 and $9 \mathrm{~K}$ under an applied field of 1200 Oe.

At $2 \mathrm{~K}$, a single signal was observed centered at $80 \mathrm{~Hz}$, while when increasing the temperature, a second contribution localized at a lower frequency appeared in the experimental frequency windows. The temperature dependence of the relaxation time for the two contributions of the magnetic susceptibility was extracted, fitting simultaneously $\chi_{M}{ }^{\prime}$ and $\chi_{M}{ }^{\prime \prime}$ with a modified extended Debye model (Figure S14 and Table S5). The relaxation time of the magnetization $(\tau)$ for the two high frequency (HF) and low frequency (LF) contributions can be fitted using the thermally dependent Raman process only $\left(\tau^{-1}=\mathrm{CT}^{\mathrm{n}}\right)$.

The best fits were obtained with $\mathrm{C}=3.93(69) \mathrm{s}^{-1} \mathrm{~K}^{-\mathrm{n}}$ and $n=6.81(16)$ and $\mathrm{C}=1.44(27) \mathrm{s}^{-1}$ $\mathrm{K}^{-\mathrm{n}}$ and $n=7.78(11)$ (Figure 6 and Figure S9) for the HF and LF contributions, respectively. The slow magnetic relaxation fraction represents the main part of the sample (about $90 \%$ of the sample) (Figure S14). One could be tempted to attribute the HF and LF contributions to the magnetic relaxation of the $\mathrm{Dy}^{\mathrm{III}}$ in $\mathrm{C}_{4 \mathrm{v}}$ and $\mathrm{D}_{3 \mathrm{~h}}$ coordination environment regarding the intensity ratio.

The compounds 1 and $\mathbf{2}$ displayed a magnetic relaxation mainly through a pure Raman process (Figure 4, Figure 6 and Figure S9), which could be justified by the applied magnetic field (cancelling of the QTM), the moderate value of the field (the direct process is not the fastest magnetic relaxation process) and the low temperature range at which the relaxation times are extracted (below $10 \mathrm{~K}$ ), leading to a negligible Orbach contribution. Recently, several Dy ${ }^{\mathrm{II}}$-based SMMs displaying pure Raman magnetic relaxation under moderate applied field in the low temperature range have been reported [43-49]. For some of the reported example in Table 1, an Orbach process can be involved in the magnetic relaxation in the high temperature range, in which an out-of-phase contribution of the magnetic susceptibility was measured. 
The variation of the dynamic parameters could be attributed to the nature of the surrounding, symmetry of the coordination sphere, as well as the nature of the matrix (crystal packing) and they cannot be easily compared.

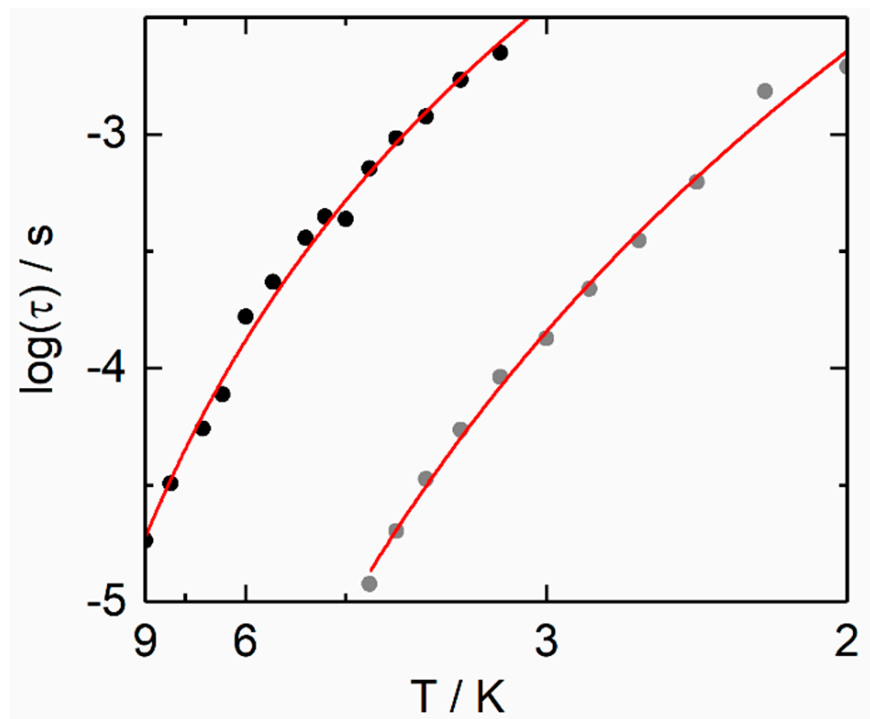

Figure 6. Temperature variation of the relaxation time for $\mathbf{2}$ for high frequency (gray spots) and low frequency (black spots) contributions in the temperature range of $2-9 \mathrm{~K}$ with the best fitted curves with Raman processes (red lines) (see text for details).

Table 1. Examples of dysprosium SMMs relaxing through Raman process.

\begin{tabular}{|c|c|c|c|}
\hline Compounds & $\begin{array}{l}\text { Local Geometries } \\
\text { Around Ln } \\
\text { III Centers }\end{array}$ & $\begin{array}{l}\text { Magnetic Properties } \\
\text { (Field Induced SMM) }\end{array}$ & Ref. \\
\hline $\begin{array}{c}{\left[\mathrm{Dy}_{2}(\mathrm{tta})_{6}(\mathrm{Q})\right] \cdot 2 \mathrm{CH}_{2} \mathrm{Cl}_{2}} \\
\text { (tta }=2 \text {-thenoyltrifluoroacetylacetonate, } \\
\mathrm{Q}=2,2^{\prime} \text {-cyclohexa-2,5-diene-1,4- } \\
\text { diylidenebis(4,7-di-tert-butyl-1,3- } \\
\text { benzodithiole-5,6-dione) }\end{array}$ & $\begin{array}{l}\text { Square antiprism } \\
\text { geometry }\end{array}$ & $\begin{array}{c}\mathrm{H}=1200 \mathrm{Oe} \\
U_{\mathrm{eff}}=26.5(2) \mathrm{K} \\
\tau_{0}=1.9(7) \times 10^{-7} \mathrm{~s} \\
\mathrm{C}=289(93) \mathrm{s}^{-1} \mathrm{~K}^{-\mathrm{n}} \\
n=1.88(39)\end{array}$ & [17] \\
\hline $\begin{array}{c}{\left[\left(\mathrm{Dy}\left(\mathrm{HB}(\mathrm{pz})_{3}\right)_{2}\right)_{2}(\mu \text {-tetraoxolene })\right] \cdot 2 \mathrm{CH}_{2} \mathrm{Cl}_{2}} \\
\left(\mathrm{HB}(\mathrm{pz})_{3}=\text { hydrotris }(\text { pyrazolyl }) \text { borate }\right. \\
(\mu \text {-tetraoxolene }=\text { chloranilate })\end{array}$ & $\begin{array}{l}\text { Triangular dodecahedral } \\
\text { geometry }\end{array}$ & $\begin{array}{c}\mathrm{H}=1600 \mathrm{Oe} \\
U_{\text {eff }}=24 \mathrm{~K} \\
\tau_{0}=3 \times 10^{-5} \mathrm{~s} \\
\mathrm{C}=2.7 \times 10^{-3} \mathrm{~s}^{-1} \mathrm{~K}^{-\mathrm{n}} \\
n=7 \text { (fixed) }\end{array}$ & [15] \\
\hline $\begin{array}{c}{\left[\mathrm{Dy}(\mathrm{acac})_{2}\left(\mathrm{CH}_{3} \mathrm{OH}\right)\right]_{2}(\mu-\mathrm{Mq})} \\
(\text { acac }=\text { acetylacetone }) \\
(\mu-\mathrm{Mq}=2 \text {-methyl-8-hydroxyquinoline })\end{array}$ & $\begin{array}{l}\text { Hexagonal bipyramid } \\
\text { geometry }\end{array}$ & $\begin{array}{c}\mathrm{H}=2000 \mathrm{Oe} \\
U_{\mathrm{eff}}=75.6 \mathrm{~K} \\
\tau_{0}=2.1 \times 10^{-8} \mathrm{~s} \\
\mathrm{C}=0.76 \mathrm{~s}^{-1} \mathrm{~K}^{-\mathrm{n}} \\
n=3.4\end{array}$ & [45] \\
\hline $\begin{array}{c}{\left[\mathrm{Dy}(\mathrm{tta})_{3}(\mathrm{mbpymNO})\right]} \\
(\mathrm{mbpymNO}= \\
\text { 4-methylbipyrimidine-2- } \mathrm{N} \text {-oxide })\end{array}$ & $\begin{array}{l}\text { Square antiprism } \\
\text { geometry }\end{array}$ & $\begin{array}{c}\mathrm{H}=1000 \mathrm{Oe} \\
U_{\text {eff }}=99.6 \mathrm{~K} \\
\tau_{0}=2.1 \times 10^{-9} \mathrm{~s} \\
\mathrm{C}=0.24 \mathrm{~s}^{-1} \mathrm{~K}^{-n} \\
n=4.9\end{array}$ & [46] \\
\hline
\end{tabular}


Table 1. Cont.

\begin{tabular}{|c|c|c|c|}
\hline Compounds & $\begin{array}{l}\text { Local Geometries } \\
\text { Around Ln }{ }^{\text {III }} \text { Centers }\end{array}$ & $\begin{array}{l}\text { Magnetic Properties } \\
\text { (Field Induced SMM) }\end{array}$ & Ref. \\
\hline $\begin{array}{c}{\left[\mathrm{Dy}(\mathrm{tta})_{3}(\text { phenNO })\right]} \\
(\text { phenNO }=1,10-\text { phenantroline-1-oxide })\end{array}$ & $\begin{array}{l}\text { Square antiprism } \\
\text { geometry }\end{array}$ & $\begin{array}{c}\mathrm{H}=1000 \mathrm{Oe} \\
U_{\text {eff }}=159.1 \mathrm{~K} \\
\tau_{0}=1.9 \times 10^{-10} \mathrm{~s} \\
\mathrm{C}=5 \times 10^{-3} \mathrm{~s}^{-1} \mathrm{~K}^{-\mathrm{n}} \\
n=5.2\end{array}$ & [46] \\
\hline $\begin{array}{c}{\left[\mathrm{Dy}(\mathrm{tmhd})_{3}(\mathrm{dppz})\right]} \\
(\mathrm{tmhd}= \\
\text { 2,2,6,6-tetramethyl-3,5-heptanedione }) \\
\left.\left(\mathrm{dppz}=\text { dipyrido[3,2-a:2' }{ }^{\prime}, 3^{\prime} \text {-c }\right] \text { phenazine }\right)\end{array}$ & $\begin{array}{c}\text { Distorted } \\
\text { square-antiprism }\end{array}$ & $\begin{array}{c}\mathrm{H}=1000 \mathrm{Oe} \\
U_{\mathrm{eff}}=247.8 \mathrm{~K} \\
\tau_{0}=2.22 \times 10^{-11} \mathrm{~s} \\
\mathrm{C}=4.28 \times 10^{-4} \mathrm{~s}^{-1} \mathrm{~K}^{-\mathrm{n}} \\
n=5.43\end{array}$ & [48] \\
\hline $\begin{array}{c}{\left[\mathrm{Dy}_{2} \mathrm{Cp}_{4}^{*}\left(\mu-\mathrm{BPh}_{4}\right)\right]\left[\mathrm{Al}\left(\mathrm{OC}\left(\mathrm{CF}_{3}\right)_{3}\right)_{4}\right]} \\
\left(\mathrm{Cp}^{*}=\right. \\
\text { 1,2,3,4,5-pentamethylcyclopentadiene }) \\
\left(\mathrm{BPh}_{4}=\text { tetraphenylborate }\right)\end{array}$ & / & $\begin{array}{c}\mathrm{H}=1000 \mathrm{Oe} \\
U_{\mathrm{eff}}=490 \mathrm{~K} \\
\tau_{0}=1.785 \times 10^{-8} \mathrm{~s} \\
\mathrm{C}=1.50 \times 10^{-4} \mathrm{~s}^{-1} \mathrm{~K}^{-\mathrm{n}} \\
n=3.86\end{array}$ & [49] \\
\hline$\left[\mathrm{Dy}(\mathrm{hfac})_{3}\left(\mathrm{~L}^{1}\right)\right]_{\mathrm{n}}$ & $\begin{array}{l}\text { Square-antiprism } \\
\text { geometry }\end{array}$ & $\begin{aligned} \mathrm{H}=1000 \mathrm{Oe} \\
\mathrm{C}=0.12(9) \mathrm{s}^{-1} \mathrm{~K}^{-n} \\
n=6.10(48)\end{aligned}$ & [43] \\
\hline$\left\{\left[\mathrm{Dy}(\mathrm{hfac})_{3}\left(\mathrm{~L}^{2}\right)\right] \cdot 0.5\left(\mathrm{CH}_{2} \mathrm{Cl}_{2}\right) \cdot 2\left(\mathrm{C}_{6} \mathrm{H}_{14}\right)\right.$ & $\begin{array}{l}\text { Square-antiprism } \\
\text { geometry }\end{array}$ & $\begin{aligned} \mathrm{H}=1000 \mathrm{Oe} \\
\mathrm{C}=0.71(6) \mathrm{s}^{-1} \mathrm{~K}^{-n} \\
\\
n=3.75(25)\end{aligned}$ & [44] \\
\hline$\left[\mathrm{Dy}(\mathrm{hfac})_{3}\left(\mathrm{~L}^{3}\right)\right]_{\mathrm{n}}$ & $\begin{array}{l}\text { Square-antiprism } \\
\text { geometry }\end{array}$ & $\begin{aligned} & \mathrm{H}=1000 \mathrm{Oe} \\
\mathrm{C}= & 125(36) \mathrm{s}^{-1} \mathrm{~K}^{-\mathrm{n}} \\
& n=2.82(13)\end{aligned}$ & [44] \\
\hline$\left[\mathrm{Dy}(\mathrm{hfac})_{3}\left(\mathrm{~L}^{4}\right)\right]_{\mathrm{n}}$ & $\begin{array}{l}\text { Square-antiprism } \\
\text { geometry }\end{array}$ & $\begin{array}{c}\mathrm{H}=1000 \mathrm{Oe} \\
\mathrm{C}=48.8(41) \mathrm{s}^{-1} \mathrm{~K}^{-\mathrm{n}} \\
n=2.73(6)\end{array}$ & [44] \\
\hline (1) & $\begin{array}{l}\text { spherical tricapped } \\
\text { trigonal prism geometry }\end{array}$ & $\begin{aligned} & \mathrm{H}=1000 \mathrm{Oe} \\
\mathrm{C}= & 175(19) \mathrm{s}^{-1} \mathrm{~K}^{-n} \\
& n=1.95(11)\end{aligned}$ & this work \\
\hline (2) & $\begin{array}{l}\text { spherical tricapped } \\
\text { trigonal prism geometry } \\
\text { and spherical capped } \\
\text { square antiprism }\end{array}$ & $\begin{array}{c}\mathrm{H}=1000 \mathrm{Oe} \\
\mathrm{C}=3.93(69) \text { and } 1.44(27) \mathrm{s}^{-1} \mathrm{~K}^{-\mathrm{n}} \\
n=6.81(16) \text { and } 7.78(11)\end{array}$ & this work \\
\hline
\end{tabular}

\section{Conclusions}

In this article, the two 4,7-di-tert-butyl-2-(3,5-di-tert-butyl-4-oxocyclohexa-2,5-dien1-ylidene)benzo[d][1,3]dithiole-5,6-dione $\left(\mathbf{L}^{1}\right)$ and 7,8-dithiabicyclo[4.2.0]octa-1,5-diene3,4-dione,2,5bis(1,1-dimethylethyl) $\left(\mathbf{L}^{2}\right)$ ligands coordinated the Dy(hfac $)_{3}$ unit. The Xray structures of the two mononuclear complexes revealed that the quinone form of the ligands is kept and dimers are identified due to the presence of remaining coordinated water molecules which allowed the formation of hydrogen bonds. Both compounds $\left[\mathrm{Dy}(\mathrm{hfac})_{3}\left(\mathrm{H}_{2} \mathrm{O}\right)\left(\mathbf{L}^{\mathbf{1}}\right)\right]$ and $\left[\mathrm{Dy}(\mathrm{hfac})_{3}\left(\mathrm{H}_{2} \mathrm{O}\right)\left(\mathbf{L}^{2}\right)\right]$ displayed a field-induced single-molecule magnet behavior, with magnetic relaxation occurring through a Raman process. Even if the general structure around the metal is similar for both compounds, slight modification of the arrangement of the dysprosium in the dimeric structures can lead to magnetic changes.

\section{Materials and Methods}

\subsection{Synthesis. General Procedures and Materials}

The precursor [Dy $\left.(\mathrm{hfac})_{3}\left(\mathrm{H}_{2} \mathrm{O}\right)_{2}\right]\left(\mathrm{hfac}^{-}=1,1,1,5,5,5\right.$-hexafluoroacetylacetonate anion) [50], 4,7-di-tert-butyl-2-(3,5-di-tert-butyl-4-oxocyclohexa-2,5-dien-1-ylidene)benzo[d] 
[1,3]dithiole-5,6-dione $\left(\mathbf{L}^{\mathbf{1}}\right)$ [30] and the 7,8-dithiabicyclo[4.2.0]octa-1,5-diene-3,4-dione,2,5bis (1,1-dimethylethyl) $\left(\mathbf{L}^{2}\right)$ [31] were synthesized following previously reported methods. All other reagents were commercially available and used without further purification.

\subsection{Synthesis of Complexes [Dy (hfac) $\left.)_{3}\left(L^{1}\right)\right]$ (1) and [Dy $\left.(h f a c)_{3}\left(L^{2}\right)\right] \cdot\left(\mathrm{C}_{6} \mathrm{H}_{14}\right)\left(\mathrm{CH}_{2} \mathrm{Cl}_{2}\right)(2)$}

$\left[D y(h f a c)_{3}\left(\mathrm{H}_{2} \mathrm{O}\right)\left(\boldsymbol{L}^{1}\right)\right](\mathbf{1})$. Notably, $16.4 \mathrm{mg}$ of $\left[\mathrm{Dy}(\mathrm{hfac})_{3}\left(\mathrm{H}_{2} \mathrm{O}\right)_{2}\right](0.02 \mathrm{mmol})$ were dissolved in $10 \mathrm{~mL}$ of $\mathrm{CH}_{2} \mathrm{Cl}_{2}$ and then added to a pink-purple solution of $10 \mathrm{~mL}$ of $\mathrm{CH}_{2} \mathrm{Cl}_{2}$ containing $10.0 \mathrm{mg}$ of $\mathbf{L}^{\mathbf{1}}(0.02 \mathrm{mmol})$. The resulting solution changed color from purple to green when adding the Dy ${ }^{\mathrm{III}}$ salt. After $20 \mathrm{~min}$ of stirring, $20 \mathrm{~mL}$ of $n$-hexane were layered at room temperature. Suitable deep green single crystals of $\mathbf{1}$ suitable for X-ray diffraction study were obtained by slow diffusion, followed by a slow evaporation in the dark. Yield (determined from isolated single crystals) $21.8 \mathrm{mg}$ (84\%). Anal. Calcd (\%) for $\mathrm{C}_{44} \mathrm{H}_{43} \mathrm{DyF}_{18} \mathrm{O}_{10} \mathrm{~S}_{2}$ : C 40.65, H 3.31; found: C 40.29, H 3.43.

[Dy $\left.(h f a c)_{3}\left(\mathrm{H}_{2} \mathrm{O}\right)\left(\mathrm{L}^{2}\right)\right] \cdot\left(\mathrm{C}_{6} \mathrm{H}_{14}\right)\left(\mathrm{CH}_{2} \mathrm{Cl}_{2}\right)(2) \cdot\left(\mathrm{C}_{6} \mathrm{H}_{14}\right)\left(\mathrm{CH}_{2} \mathrm{Cl}_{2}\right)$. Notably, $16.4 \mathrm{mg}$ of [Dy $(\mathrm{hfac})_{3}$ $\left.\left(\mathrm{H}_{2} \mathrm{O}\right)_{2}\right](0.02 \mathrm{mmol})$ were dissolved in $10 \mathrm{~mL}$ of $\mathrm{CH}_{2} \mathrm{Cl}_{2}$ and then added to a violet solution of $10 \mathrm{~mL}$ of $\mathrm{CH}_{2} \mathrm{Cl}_{2}$ containing $5.6 \mathrm{mg}$ of $\mathbf{L}^{2}(0.02 \mathrm{mmol})$. The resulting solution changed color from violet to green when adding the Dy ${ }^{\mathrm{III}}$ salt. After $15 \mathrm{~min}$ of stirring, $20 \mathrm{~mL}$ of $n$-hexane were layered at room temperature. Suitable deep green single crystals of (2) $\cdot\left(\mathrm{C}_{6} \mathrm{H}_{14}\right)\left(\mathrm{CH}_{2} \mathrm{Cl}_{2}\right)$ for $\mathrm{X}$-ray diffraction study were obtained by slow diffusion followed by a slow evaporation in the dark. Yield (determined from isolated single crystals) $12.8 \mathrm{mg}$ (59\%). Anal. Calcd (\%) for $\mathrm{C}_{29} \mathrm{H}_{23} \mathrm{DyF}_{18} \mathrm{O}_{9} \mathrm{~S}_{2}$ : C 32.12, H 2.12; found: C 31.89, H 2.13.

\subsection{Crystallography}

Single crystals of $\mathbf{L}^{\mathbf{1}}, \mathbf{1}$ and $\mathbf{2} \cdot\left(\mathrm{C}_{6} \mathrm{H}_{14}\right)\left(\mathrm{CH}_{2} \mathrm{Cl}_{2}\right)$ were mounted on a D8 VENTURE Bruker-AXS diffractometer for data collection ( $\mathrm{MoK}_{\alpha}$ radiation source, $\lambda=0.71073 \AA$ ), from the diffractometric center X (CDIFX), University of Rennes 1, France (Table S1). SHELXT program [51] was used to solve the structures with a direct method and refinements were done with the SHELXL-14/7 program [52] using a full matrix least-squares method on $\mathrm{F}^{2}$. It is worth to notice that the bad quality of the obtained single crystal does not allowed a high level of refinement. Moreover, 2 contains large solvent accessible voids in which residual peak of diffraction were observed and SQUEEZE procedure of PLATON [53] was performed. Residual electronic density and the volume of voids are in agreement with $8 n$-hexane and 8 dichloromethane molecules per asymetric unit. CCDC number is 2,039,846-2,039,848 for compounds $\mathbf{L}^{\mathbf{1}}, \mathbf{1}$ and $\mathbf{2} \cdot\left(\mathrm{C}_{6} \mathrm{H}_{14}\right)\left(\mathrm{CH}_{2} \mathrm{Cl}_{2}\right)$, respectively.

\subsection{Physical Measurements}

The elemental analyses of the compounds were performed at the Centre Régional de Mesures Physiques de l'Ouest, Rennes. The static susceptibility measurements were performed on solid polycrystalline samples with a Quantum Design MPMS-XL SQUID magnetometer. The following values of magnetic field were used $0.2 \mathrm{kOe}, 2 \mathrm{kOe}$ and $10 \mathrm{kOe}$ respectively for the temperature range of $2-20 \mathrm{~K}, 20-80 \mathrm{~K}$ and $80-300 \mathrm{~K}$ in order to prevent any saturation effect. The ac magnetic susceptibility measurements were performed on both Quantum Design MPMS-XL SQUID magnetometer (1-1000 Hz frequency range) and Quantum Design PPMS (10-10000 Hz frequency range) system equipped with an AC/DC probe. Immobilized selected and crunched single crystals were employed to realize the magnetic measurements and the latter were all corrected for the diamagnetic contribution as calculated with Pascal's constants.

Supplementary Materials: The following are available online at https://www.mdpi.com/2312 $-7481 / 7 / 2 / 24 / s 1$, Scheme S1. Coordination reactions leading to the formation of complexes 1 and 2. Figure S1. ORTEP view of the asymmetric unit for 1 . Thermal ellipsoids are drawn at $30 \%$ probability. Hydrogen atoms are omitted for clarity. Figure S2. Orthogonal arrangement of two neighboring molecules in the crystal packing of $\mathbf{1}$. Figure S3. ORTEP view of the asymmetric unit for 2. $\left(\mathrm{C}_{6} \mathrm{H}_{14}\right)\left(\mathrm{CH}_{2} \mathrm{Cl}_{2}\right)$. Thermal ellipsoids are drawn at $30 \%$ probability. Hydrogen atoms and solvent molecules of crystallization are omitted for clarity; Figure S4. Crystal packing of $2 \cdot\left(\mathrm{C}_{6} \mathrm{H}_{14}\right)\left(\mathrm{CH}_{2} \mathrm{Cl}_{2}\right)$ 
showing the alternation between ordered and disordered layers of dimers; Figure S5. Representation of the four dimers constituting the asymmetric unit with $\mathrm{H} \cdots \mathrm{F}$ (dashed brown lines) and $\mathrm{F} \cdots \mathrm{F}$ (dashed black lines) contacts; Figure S6. Frequency dependence of $\chi_{M}{ }^{\prime}$ and $\chi_{M}$ " between 0 and 4000 Oe for 1 at $2 \mathrm{~K}$ in the frequency range of $1-1000 \mathrm{~Hz}$ (left) and 100-10000 Hz (right); Figure S7. Frequency dependence of $\chi_{M}{ }^{\prime}$ (above) and $\chi_{M}{ }^{\prime \prime}$ (below) between 2 and $7 \mathrm{~K}$ at 1600 Oe for 1; Figure S8. Frequency dependence of the in-phase $\left(\chi_{M}^{\prime}\right)$ and out-of-phase $\left(\chi_{M}{ }^{\prime \prime}\right)$ components of the ac susceptibility measured on powder at $2 \mathrm{~K}$ and 1600 Oe with the best fitted curves (red lines) for $\mathbf{1}$.; Figure S9. Linear plot of the temperature variation of the relaxation time for $\mathbf{1}$ in the temperature range of $2-3.5 \mathrm{~K}$ (blue spots) and 2 in the temperature range of $2-9 \mathrm{~K}$ (blue spots) with the best fitted curve with the modified Arrhenius law (red line); Figure S10. Normalized Argand plot for 1 between 2 and 4 K.; Figure S11. Frequency dependence of $\chi_{M}{ }^{\prime}$ between 0 and 4000 Oe for 2 at $2 \mathrm{~K}$ in the frequency range of 10-10000 Hz.; Figure S12. Frequency dependence of $\chi_{\mathrm{M}}{ }^{\prime}$ between 2 and $9 \mathrm{~K}$ at 1200 Oe for 2; Figure S13. Frequency dependence of the in-phase $\left(\chi_{M}{ }^{\prime}\right)$ and out-of-phase $\left(\chi_{M}{ }^{\prime \prime}\right)$ components of the ac susceptibility measured on powder at $3.5 \mathrm{~K}$ and 1200 Oe with the best fitted curves (red lines) for 2.; Figure S14. Normalized Argand plot for 2 between 2 and 9 K.; Table S1: X-ray crystallographic data of $\mathbf{L}^{\mathbf{1}}, \mathbf{1}$ and $\mathbf{2}$; Table S2: SHAPE analysis of the coordination polyhedron around the Dy ${ }^{\mathrm{III}}$ center for 1; Table S3: SHAPE analysis of the coordination polyhedra around the Dy ${ }^{I I I}$ centers for 1 for 2; Table S4: Best fitted parameters $\left(\chi_{T}, \chi_{S}, \tau\right.$ and $\left.\alpha\right)$ with the modified extended Debye model for 1 at 1600 Oe in the temperature range 2-3.5 K. Table S5. Best fitted parameters $\left(\tau_{1}, \alpha_{1}, \chi_{1 T}, \tau_{2}, \alpha_{2}, \chi_{2 T}\right.$ and $\left.\chi_{S}\right)$ with the modified extended Debye model for 2 at 1200 Oe in the temperature range $2-9 \mathrm{~K}$.

Author Contributions: K.M., S.N., V.K., B.L. and F.P. performed the organic syntheses and performed the coordination chemistry and crystallizations, V.D. realized the single crystal X-ray diffraction experiments and refined the X-ray structures; O.C. and J.F.G. performed and analyzed the magnetic measurements. V.C. discussed the idea and the results and commented on the manuscript. F.P. and V.K. conceived and designed the experiments and contributed to the writing of the article. All authors have read and agreed to the published version of the manuscript.

Funding: This work was supported by CNRS, Université de Rennes 1, France-Russia MULTISWITCH PRC Grant (N²27606), Russian Foundation for Basic Research (grant 19-53-15007 NCNI_a) and the European Commission through the ERC-CoG 725184 MULTIPROSMM (project n. 725184).

Acknowledgments: V.K., S.N., K.M. and V.C. thank the "Analytical Center IOMC RAS" and Russian Federal Program for development of science and technology for 2014-2020 (project identifier is RFMEFI62120 × 0040).

Conflicts of Interest: The authors declare no conflict of interest. The founding sponsors had no role in the design of the study; in the collection, analyses, or interpretation of data; in the writing of the manuscript, and in the decision to publish the results.

\author{
Abbreviations \\ The following abbreviations are used in this manuscript: \\ TTF Tetrathiafulvalene \\ SMM Single Molecule Magnet \\ QTM Quantum Tunneling of the Magnetization \\ $\mathrm{CH}_{2} \mathrm{Cl}_{2}$ dichloromethane \\ hfac- $\quad 1,1,1,5,5,5$-hexafluoroacetylacetonate
}

\title{
References
}

1. Patai, S. (Ed.) The Chemistry of the Quinoid Compounds, Part 1 and 2; Wiley: New York, NY, USA, 1974.

2. Pierpont, C.G.; Buchanan, R.M. Transition metal complexes of $o$-benzoquinone, $o$-semiquinone, and catecholate ligands. Coord. Chem. Rev. 1981, 38, 45-87. [CrossRef]

3. Pierpont, C.G.; Lange, C.W. The chemistry of transition metal complexes containing catechol and semiquinone ligands. Prog. Inorg. Chem. 1994, 41, 331-442.

4. Pierpont, C.G. Studies on Charge Distribution and Valence Tautomerism in Transition Metal Complexes of Catecholate and Semiquinonate Ligands. Coord. Chem. Rev. 2001, 216-217, 99-125. [CrossRef] 
5. Bubnov, M.P.; Kozhanov, K.A.; Skorodumova, N.A.; Cherkasov, V.K. Photo- and Thermosensitive Molecular Crystals. Valence Tautomeric Interconversion as the Cause of the Photomechanical Effect in Crystals of Bis(dioxolene)cobalt Complex. Inorg. Chem. 2020, 59, 6679-6683. [CrossRef] [PubMed]

6. Caneschi, A.; Dei, A.; Gatteschi, D.; Sorace, L.; Vostrikova, K. Antiferromagnetic coupling in a gadolinium(III) semiquinonato complex. Angew. Chem. Int. Ed. 2000, 39, 246-248. [CrossRef]

7. Caneschi, A.; Dei, A.; Gatteschi, D.; Massa, C.A.; Pardi, L.A.; Poussereau, S.; Sorace, L. Evaluating the magnetic anisotropy in molecular rare earth compounds. Gadolinium derivatives with semiquinone radical and diamagnetic analogues. Chem. Phys. Lett. 2003, 371, 694-699. [CrossRef]

8. Caneschi, A.; Dei, A.; Gatteschi, D.; Poussereau, S.; Sorace, L. Antiferromagnetic coupling between rare earth ions and semiquinones in a series of 1:1 complexes. Dalton Trans. 2004, 7, 1048-1055. [CrossRef]

9. Claiser, N.; Souhassou, M.; Lecomte, C.; Gillon, B.; Carbonara, C.; Caneschi, A.; Dei, A.; Gatteschi, D.; Bencini, A.; Pontillon, Y.; et al. Combined charge and spin density experimental study of the yttrium(III) semiquinonato complex Y(HBPz(3))(2)(DTBSQ) and DFT calculations. J. Phys. Chem. B 2005, 109, 2723-2732. [CrossRef]

10. Reynolds, R.A.; Coucouvanis, D. Mixed Carboxylate/Catecholate Polynuclear Complexes. Integral Association of Trivalent Lanthanide Ions with Mn4 Units in the Pentanuclear Mn4LaCl and Mn4Tb Clusters. J. Am. Chem. Soc. 1998, 120, 209-210. [CrossRef]

11. Zhu, D.-H.; Kappel, M.J.; Raymond, K.N. Coordination chemistry of lanthanide catecholates. Inorg. Chim. Acta 1988, 147, 115-121. [CrossRef]

12. Kuzyaev, D.M.; Vorozhtsov, D.L.; Druzhkov, N.O.; Lopatin, M.A.; Baranov, E.V.; Cherkasov, A.V.; Fukin, G.K.; Abakumov, G.A.; Bochkarev, M.N. 3,5-Di-tert-butyl-o-benzoquinone complexes of lanthanides. J. Organomet. Chem. 2012, 698, 35-41. [CrossRef]

13. Pointillart, F.; Kuropatov, V.; Mitin, A.; Maury, O.; Le Gal, Y.; Golhen, S.; Cador, O.; Cherkasov, V.; Ouahab, L. Lanthanide-Based Dinuclear Complexes Involving an o-Quinone-Tetrathiafulvalene-o-Quinone Bridging Ligand: X-ray Structures, Magnetic and Photophysical properties. Eur. J. Inorg. Chem. 2012, 4708-4718. [CrossRef]

14. Pointillart, F.; Klementieva, S.; Kuropatov, V.; Le Gal, Y.; Golhen, S.; Cador, O.; Cherkasov, V.; Ouahab, L. A single molecule magnet behavior in a $D_{3 \mathrm{~h}}$ symmetry Dy(III) complex involving a quinone-tetrathiafulvalene-quinone bridge. Chem. Commun. 2012, 48, 714-716. [CrossRef]

15. Dunstan, M.A.; Rousset, E.; Boulon, M.-E.; Gable, R.W.; Sorace, L.; Boskovic, C. Slow magnetisation relaxation in tetraoxolenebridged rare earth complexes. Dalton Trans. 2017, 46, 13756-13767. [CrossRef]

16. Gonzalez, J.F.; Cador, O.; Ouahab, O.; Norkov, S.; Kuropatov, V.; Pointillart, F. Field-Induced Dysprosium Single-Molecule Magnet Involving a Fused o-Semiquinone-Extended-Tetrathiafulvalene-o-Semiquinone Bridging Triad. Inorganics 2018, 6, 45. [CrossRef]

17. Pointillart, F.; Gonzalez, J.F.; Montigaud, V.; Tesi, L.; Cherkasov, V.; Le Guennic, B.; Cador, O.; Ouahab, L.; Sessoli, R.; Kuropatov, V. Redox- and solvato-magnetic switching in a tetrathiafulvalene-based triad single-molecule magnet. Inorg. Chem. Front. 2020, 7 , 2322-2334. [CrossRef]

18. Tiaouinine, S.; Gonzalez, J.F.; Montigaud, V.; Mattei, C.A.; Dorect, V.; Kaboub, L.; Cherkasov, V.; Cador, O.; Le Guennic, B.; Ouahab, L.; et al. Redox Modulation of Field-Induced Tetrathiafulvalene-Based Single-Molecule Magnets of Dysprosium. Magnetochemistry 2020, 6, 34. [CrossRef]

19. Zhang, P.; Perfetti, M.; Kern, M.; Hallmen, P.P.; Ungur, L.; Lenz, S.; Ringenberg, M.R.; Trey, W.; Stoll, H.; Rauhut, G.; et al. Exchange coupling and single molecule magnetism in redox-active tetraoxolene-bridged dilanthanide complexes. Chem. Sci. 2018, 9, 1221-1230. [CrossRef] [PubMed]

20. Lefeuvre, B.; Gonzalez, J.F.; Gendron, F.; Dorcet, V.; Riobé, F.; Cherkasov, V.; Maury, O.; Le Guennic, B.; Cador, O.; Kuropatov, V.; et al. Redox-Modulations of Photophysical and Single-Molecule Magnet Properties in Ytterbium Complexes Involving Extended-TTF Triads. Molecules 2020, 25, 492. [CrossRef]

21. Guo, F.-S.; Day, B.-M.; Chen, Y.-C.; Tong, M.-L.; Mansikkamäki, A.; Layfield, R.A. A Dysprosium Metallocene Single-Molecule Magnet Functioning at the Axial Limit. Angew. Chem. Int. Ed. 2017, 56, 11445-11449. [CrossRef] [PubMed]

22. Goodwin, C.A.P.; Ortu, F.; Reta, D.; Chilton, N.F.; Mills, D.P. Molecular magnetic hysteresis at 60 kelvin in dysprosocenium. Nature 2017, 548, 439-442. [CrossRef]

23. McClain, K.R.; Gould, C.A.; Chakarawet, K.; Teat, S.J.; Groshens, T.J.; Long, J.R.; Harvey, B.G. High temperature magnetic blocking and magneto-structural correlations in a series of dysprosium(III) metallocenium single-molecule magnets. Chem. Sci. 2018, 9, 8492-8503. [CrossRef] [PubMed]

24. Guo, F.-S.; Day, B.-M.; Chen, Y.-C.; Tong, M.-L.; Mansikkamäki, A.; Layfield, R.A. Magnetic hysteresis up to 80 kelvin in a dysprosium metallocene single-molecule magnet. Science 2018, 362, 1400-1403. [CrossRef] [PubMed]

25. Martyanov, K.; Kuropatov, V. Functionalized o-Quinones: Concepts, Achievements and Prospects. Inorganics 2018, 6, 48. [CrossRef]

26. Valade, L.; Tanaka, H. Molecular Materials; Bruce, D.W., O’Hare, D., Walton, R.I., Eds.; John \& Sons, Inc.: Hoboken, NJ, USA, 2010.

27. Zadrozny, J.M.; Niklas, J.; Poluektov, O.G.; Freedman, D.E. Millisecond Coherence Time in a Tunable Molecular Electronic Spin Qubit. ACS Cent. Sci. 2015, 1, 488-492. [CrossRef] [PubMed]

28. Atzori, M.; Morra, E.; Tesi, L.; Albino, A.; Chiesa, M.; Sorace, L.; Sessoli, R. Quantum Coherence Times Enhancement in Vanadium(IV)-based Potential Molecular Qubits: The key Role of the Vanadyl Moiety. J. Am. Chem. Soc. 2016, 138, 11234-11244. [CrossRef] [PubMed] 
29. Graham, M.J.; Yu, C.-J.; Krzyaniak, M.D.; Wasielewski, M.R.; Freedman, D.E. Synthetic Approach To Determine the Effect of Nuclear Spin Distance on Electronic Spin Decoherence. J. Am. Chem. Soc. 2017, 139, 3196-3201. [CrossRef] [PubMed]

30. Norkov, S.V.; Cherkasov, A.V.; Shavyrin, A.S.; Arsenyev, M.V.; Kuropatov, V.A.; Cherkasov, V.K. Annulation of 1,3-dithiole ring to sterically hindered o-quinone core. Novel ditopic redox-active ligands. Beilstein J. Org. Chem. 2021, 17, 273-282. [CrossRef]

31. Cherkasov, V.K.; Abakumov, G.A.; Fukin, G.K.; Klementyeva, S.V.; Kuropatov, V.A. Sterically Hindered o-Quinone Annulated with Dithiete: A Molecule Comprising Diolate and Dithiolate Coordination Sites. Chem. Eur. J. 2012, 18, 13821-13827. [CrossRef]

32. Martyanov, K.A.; Cherkasov, V.K.; Abakumov, G.A.; Samsonov, M.A.; Khrizanforova, V.V.; Budnikova, Y.H.; Kuropatov, V.A. New sterically-hindered o-quinones annelated with metal-dithiolates: Regiospecificity in oxidative addition reactions of a bifacial ligand to the Pd and Pt complexes. Dalton Trans. 2016, 45, 7400-7405. [CrossRef]

33. Martyanov, K.A.; Cherkasov, V.K.; Abakumov, G.A.; Baranov, E.V.; Shavyrin, A.S.; Kuropatov, V.A. Regioisomerism in coordination chemistry: Oxidative addition of a bifunctional ligand to palladium, stabilized with 1,2-bis(diphenylphosphino)ethane. Dalton Trans. 2017, 46, 16783-16786. [CrossRef]

34. Martyanov, K.A.; Abakumov, G.A.; Baranov, E.V.; Khrizanforova, V.V.; Khrizanforov, M.N.; Kholin, K.V.; Budnikova, Y.H.; Kuropatov, V.A.; Cherkasov, V.K. Pd ${ }^{\mathrm{II}}(\mathrm{P}-\mathrm{P})$ derivatives of o-quinone annulated with dithiete cycle: Electrochemical properties and coordination regioisomerism. Eur. J. Inorg. Chem. 2020, 2020, 4350-4357. [CrossRef]

35. Llunell, M.; Casanova, D.; Cirera, J.; Alemany, P.; Alvarez, S. SHAPE Program for the Stereochemical Analysis of Molecular Fragments by Means of Continuous Shape Measures and Associated Tools; Departament de Quimica Fisica, Departament de Quimica Inorganica and Institut de Quimica Teorica i Computacional-Universitat de Barcelona: Barcelona, Spain, 2013.

36. Kahn, O. Molecular Magnetism; VCH: Weinhem, Germany, 1993.

37. Dekker, C.; Arts, A.F.M.; Wijn, H.W.; van Duyneveldt, A.J.; Mydosh, J.A. Activated dynamics in a two dimensional Ising spin glass: Rb2Cu1-xCoxF4. Phys. Rev. B 1989, 40, 11243-11251. [CrossRef] [PubMed]

38. Cole, K.S.; Cole, R.H. Dipersion and Absorption in Dielectrics I. Alternating Current Characteristics. J. Chem. Phys. 1941, 9 , 341-351. [CrossRef]

39. Singh, A.; Shrivastava, K.N. Optical-acoustic two-phonon relaxation in spin systems. Phys. Status Solidi B 1979, 95, $273-277$. [CrossRef]

40. Shirivastava, K.N. Theory of Spin-Lattice Relaxation. Phys. Status Solidi B 1983, 177, 437-458. [CrossRef]

41. Goodwin, C.A.P.; Reta, D.; Ortu, F.; Chilton, N.F.; Mills, D.P. Synthesis and Electronic Structures of Heavy Lanthanide Metallocenium Cations. J. Am. Chem. Soc. 2017, 139, 18714-18724. [CrossRef]

42. Abragam, A.; Bleaney, B. Electron Paramagnetic Resonance of Transition Ions; Clarendon Press: Oxford, UK, 1970.

43. Mattei, C.A.; Montigaud, V.; Gendron, F.; Denis-Quanquin, S.; Dorcet, V.; Giraud, N.; Riobé, F.; Argouarch, G.; Maury, O.; Le Guennic, B.; et al. Solid-state versus solution investigation of a luminescent chiral BINOL-derived bisphosphate single-molecule magnet. Inorg. Chem. Front. 2021. Advance Article. [CrossRef]

44. Mattei, C.A.; Montigaud, V.; Dorect, V.; Riobé, F.; Argouarch, G.; Maury, O.; Le Guennic, B.; Cador, O.; Lalli, C.; Pointillart, F. Luminescent dysprosium single-molecule magnets made from designed chiral BINOL-derived bisphosphate ligands. Inorg. Chem. Front 2021. Advance Article. [CrossRef]

45. Zhang, W.-Y.; Tian, Y.-M.; Li, H.-F.; Chen, P.; Sun, W.-B.; Zhang, Y.-Q.; Yan, P.-F. A series of dinuclear Dy(III) complexes bridged by 2-methyl-8-hydroxylquioline: Replacement on the periphery coordinated $\beta$-diketonate terminal leads to different single-molecule magnetic properties. Dalton Trans. 2016, 45, 3863-3873. [CrossRef]

46. Diaz-Ortega, I.F.; Herrera, J.M.; Aravena, D.; Ruiz, E.; Gupta, T.; Rajaraman, G.; Nojiri, H.; Colacio, E. Designing a Dy2 DingleMolecule Magnet with Two Well-Differentiated Relaxation Processes by using a Nonsymmetric Bis-bidentate Bipyrimidine-Noxide Ligand: A comparison with mononuclear Counterpart. Inorg. Chem. 2018, 57, 6362-6375. [CrossRef]

47. Fondo, M.; Corredoira-Vazquez, J.; Garcia-Deibe, A.M.; Sanmartin-Matalobos, J.; Herrera, J.M.; Colacio, E. Field-Induced Single Molecule Magnets of Phosphine- and Asine-Oxides. Front. Chem. 2018, 6, 420. [CrossRef] [PubMed]

48. Cen, P.; Liu, X.; Ferrando-Soria, J.; Zhang, Y.-Q.; Xie, G.; Chen, S.; Pardo, E. Capping N-Donor Ligands Modulate the Magnetic Dynamics of Dy ${ }^{I I I} \beta$-Diketonate Single-Ion Magnets with $D_{4 d}$ Symmetry. Chem. Eur. J. 2019, 25, 3884-3892. [CrossRef] [PubMed]

49. Errulat, D.; Gabidullin, B.; Mansikkamaki, A.; Murugesu, M. Two Heads are Better than One: Improving Magnetic Relaxation in the Dysprosium Metallocene upon Dimerization by Use of an Exceptionally Weakly-Coordinating Anion. Chem. Commun. 2020, 56, 5937-5940. [CrossRef] [PubMed]

50. Richardson, M.F.; Wagner, W.F.; Sands, D.E. Rare-earth trishexafluoroacetylacetonates and related compounds. J. Inorg. Nucl. Chem. 1968, 30, 1275-1289. [CrossRef]

51. Sheldrick, G.M. SHELXT_-Integrated space-group and crystal-structure determination. Acta Crystallogr. Sect. A Found Adv. 2015, 71,3-8. [CrossRef] [PubMed]

52. Sheldrick, G.M. Crystal structure refinement with SHELXL. Acta Crystallogr. Sect. C 2015, 71, 3-8.

53. Spek, A.L. Single-crystal structure validation with the program PLATON. J. Appl. Crystallogr. 2003, 36, 7-13. [CrossRef] 